\title{
De Barsy syndrome and ATP6V0A2-CDG
}

European Journal of Human Genetics (2010) 18, 526; doi:10.1038/ ejhg.2009.218; published online 16 December 2009

We read with interest the nice review of Morava et al ${ }^{1}$ on the autosomal recessive cutis laxa syndromes. The authors mention the De Barsy syndrome and state that the genetic background of the De Barsy syndrome has not yet been identified. However, in the paper by Kornak et $a l^{2}$ on impaired glycosylation and cutis laxa caused by mutations in ATP6VOA2 (ATP6V0A2-CDG according to the novel nomenclature ${ }^{3,4}$ ), one of the patients (see patient CoFe in Table 1 of Kornak et $\mathrm{al}^{2}$ ) shows the full clinical picture of the De Barsy syndrome, including cutis laxa, facial dysmorphy, dwarfism, psychomotor retardation, dystonia, congenital hip dysplasia, and corneal dystrophy necessitating repeated corneal transplantation. These data suggest that a subgroup of patients with De Barsy syndrome ${ }^{5}$ belongs to the spectrum of ATP6V0A2-CDG. Another cause of De Barsy syndrome has very recently been identified as mutations in PYCR1, coding for a mitochondrial enzyme involved in proline metabolism. ${ }^{6}$ Therefore, we recommend a systematic screen for ATP6V0A2-CDG and for mutations in PYCR1 in patients with De Barsy syndrome.

Elisa Leao-Teles ${ }^{1}$, Dulce Quelhas ${ }^{2}$, Laura Vilarinho ${ }^{2}$ and Jaak Jaeken ${ }^{3}$

${ }^{1}$ Metabolic Unit, Department of Pediatrics, San Joao, Hospital, Porto, Portugal; ${ }^{2}$ Department of Clinical Biology, Institute of Medical Genetics Jacinto de Magalhães, Porto, Portugal; ${ }^{3}$ Department of Pediatrics, Center for Metabolic Disease, University Hospital Gasthuisberg, Leuven, Belgium E-mail: jaak.jaeken@uzleuven.be

1 Morava E, Guillard M, Lefeber DJ, Wevers RA: Autosomal recessive cutis laxa syndrome revisited. Eur J Hum Genet 2009; 17: 1099-1110.

2 Kornak U, Reynders E, Dimopoulou A et al: Impaired glycosylation and cutis laxa caused by mutations in the vesicular H+-ATPase subunit ATP6VOA2. Nat Genet 2008; 40: 32-34.

3 Jaeken J, Hennet T, Freeze HH, Matthijs G: On the nomenclature of congenital disorders of glycosylation (CDG). J Inherit Metab Dis 2008; 31: 669-672.

4 Jaeken J, Hennet T, Matthijs G, Freeze HH: CDG nomenclature: time for a change. Biochim Biophys Acta 2009; 1792: 825-826.

5 Kivuva EC, Parker MJ, Cohen MC, Wagner BE, Sobey G: De Barsy syndrome: a review of the phenotype. Clin Dysmorphol 2008; 17: 99-107.

6 Reversade B, Escande Beillard N, Dimopoulou A et al: Mutations in PYCR1 cause cutis laxa with progeroid features. Nat Genet 2009; 41: 1016-1021.

\section{Reply to Leao-Teles et al}

European Journal of Human Genetics (2010) 18, 526; doi:10.1038/ ejhg.2009.219; published online 16 December 2009

We appreciate the comments ${ }^{1}$ on our review on autosomal recessive cutis laxa syndromes, ${ }^{2}$ especially the novel information on the
Portuguese patient $\mathrm{CoFe}^{3}$ (Table 1, Kornak et al), who was diagnosed with a combined $\mathrm{N}$ - and O-linked glycosylation disorder and ATP6V0A2-CDG. De Barsy syndrome is a challenging diagnosis, and has overlapping features with ARCL type 2, including cutis laxa, short stature, late closure of the fontanel, congenital hip dysplasia, some aspects of facial dysmorphism and psychomotor retardation. ${ }^{4}$ Still, dystonic movements and progressive corneal abnormalities are highly suggestive of De Barsy syndrome. So far no cobble-stone-like brain dysgenesis has been observed in De Barsy syndrome patients. Although the clinical differentiation is not always straightforward, progeroid features, the presence of pergamen-like skin and the absence of subcutaneous fat are distinctive. ${ }^{2}$ Interestingly, some of the patients, recently reported to have PYCR1 mutations, were previously diagnosed with De Barsy syndrome, ${ }^{5}$ while other De Barsy patients were found to not harbour PYCR1 mutations (unreported data), thus supporting genetic heterogeneity. We would appreciate further description and photo documentation of this unique patient, reported by Leao-Teles, as in our own cohort of six patients with De Barsy syndrome and those studied by Kornak et al (personal communication) none of the children had either N-linked or O-linked glycosylation abnormalities, nor mutations in the ATP6VOA2 gene. Eye anomalies are common in $\mathrm{N}$-glycosylation disorders, ${ }^{6}$ and strabismus and high myopia have been reported in combined glycosylation disorders. ${ }^{4}$ The exceptional observation of corneal abnormalities with a movement disorder in association with ATP6V0A2-CDG indeed widens the range of symptoms evoking glycosylation studies in patients with cutis laxa.

\section{CONFLICT OF INTEREST}

The authors declare no conflict of interest.

Eva Morava ${ }^{1}$, Mailys Guillard ${ }^{2}$, Dirk J Lefeber ${ }^{2}$ and Ron A Wevers ${ }^{2}$

${ }^{1}$ Department of Paediatrics, Radboud University Nijmegen Medical Centre, Nijmegen, The Netherlands; ${ }^{2}$ Laboratory of Paediatrics and Neurology, Radboud University Nijmegen Medical Centre, Nijmegen, The Netherlands E-mail: E.Morava@cukz.umcn.nl

1 Leao-Teles E, Quelhas D, Vilarinho L, Jaeken J: De Barsy syndrome and ATP6VOA2-CDG. Eur J Human Genet 2010; 18: 526.

2 Morava E, Guillard M, Lefeber DJ, Wevers RA: Autosomal recessive cutis laxa syndrome revisited. Eur J Hum Genet 2009; 17: 1099-1110.

3 Kornak U, Reynders E, Dimopoulou A et al: Impaired glycosylation and cutis laxa caused by mutations in the vesicular H+-ATPase subunit ATP6VOA2. Nat Genet 2008; 40: $32-34$

4 Hucthagowder V, Morava E, Kornak U et al: Loss-of-function mutations in ATP6VOA2 impair vesicular trafficking, tropoelastin secretion and cell survival. Hum Mol Genet 2009; 18: 2149-2165.

5 Reversade B, Escande-Beillard N, Dimopoulou A et al: Mutations in PYCR1 cause cutis laxa with progeroid features. Nat Genet 2009; 41: 1016-1021.

6 Morava E, Wosik HN, Sykut-Cegielska J et al: Ophthalmological abnormalities in children with congenital disorders of glycosylation type I. Br J Ophthalmol 2009; 93: 350-354 